\title{
Cera System
}

\section{Electrically Conductive Ceramic Linings}

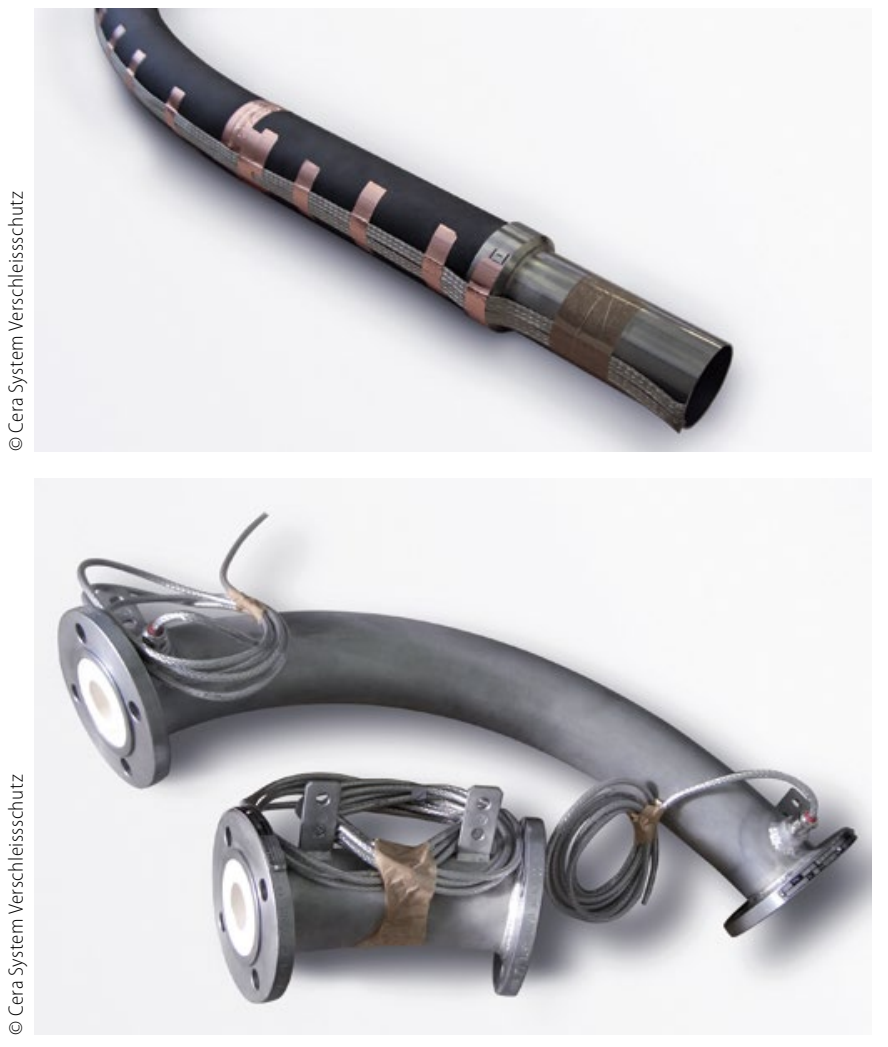

Cera System Verschleissschutz GmbH, based in Hermsdorf, is expanding its product portfolio with ceramically lined pipes, which distinguish themselves due to their antistatic characteristic. The use of such piping predominantly occurs in industries which pneumatically transport electrostatically charged materials. The company thereby makes a valuable contribution to the topic occupational and workplace safety.

Especially glass fibre reinforced plastics granulates can establish enormous loads, which can quickly lead to undesired lightning discharges. The reason lies in the ceramic lining of most pipe parts: it is electrically insulating.

Cera System faces this problem with the use of electrically conductible ceramic as well as with contact adhesive strips and earthing straps, which are applied to ceramic surface. The effect: an equipotential bonding and a charge conducting can be thereby achieved.

The earthing strap can be attached to the appropriate earthing system either directly on the adjacent pipe parts or by means of a cable lug. The in this fashion electrically connected ceramic is wrapped in conductible glass fibre reinforced plastic or cemented in a steel shell.

It should be noted here: If the ceramic is incorporated into a steel shell, the earthing conductor must be electrically connected to the steel shell or be appropriately led out of the shell. If the earthing straps are welded onto the steel shells, they can be connected to an appropriate earthing system.

POLISH YOUR KNOWLEDGE WITH IST

IST - International Surface Technology - the English „Best of" issue of JOT, Germany's leading Magazine for Surface Technology.

\section{Register now}

for your free trial subscription:

www.my-specialized-

knowledge.com/JOT-IST
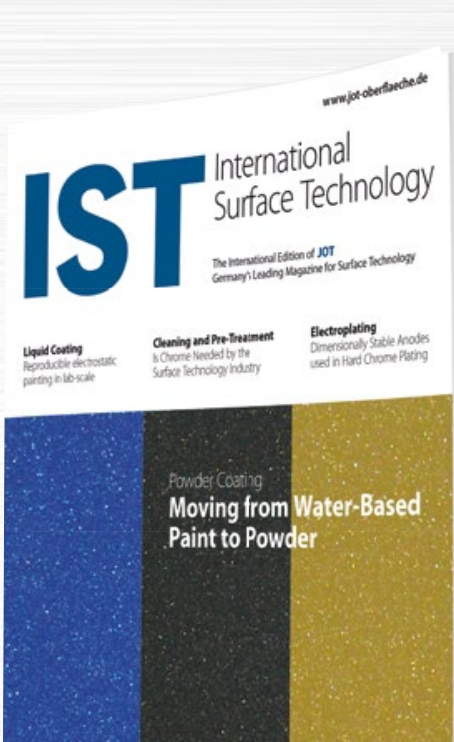

Register now!

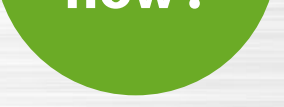

$\checkmark 3$ issues per year

$\checkmark$ including eMagazine

$\checkmark$ free access to the online archive

$\checkmark$ cancel at any time 